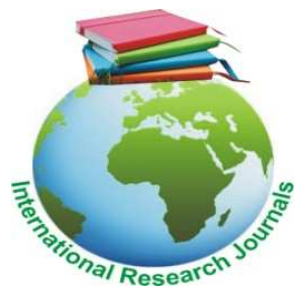

Journal of Medicine and Medical Sciences Vol. 8(3) pp. 025-030, May 2017

Available online http://www.interesjournals.org/JMMS

DOI: http:/dx.doi.org/10.14303/jmms.2017.032

Copyright (C) 2017 International Research Journals

Full Length Research Paper

\title{
Treatment outcome of pulmonary tuberculosis patients in a tertiary hospital in Bauchi Northeastern Nigeria
}

\author{
*Yusuf B Jibrin', Sabiu A Gwalabe', Jacob A Dunga', Mohammed M Abdull² \\ ${ }^{1}$ Department of Medicine, Abubakar Tafawa University Teaching Hospital, Bauchi Nigeria \\ ${ }^{2}$ Department of Ophthalmology, Abubakar Tafawa University Teaching Hospital, Bauchi Nigeria \\ ${ }^{*}$ Corresponding Author's E-mail:ybjibrin@yahoo.co.uk
}

\begin{abstract}
Pulmonary Tuberculosis (PTB) remains a major public health concern in both developing and developed countries, but the impact is much felt in sub-Saharan Africa and Asia, with high predisposing risk factor of co-morbidities of poverty, and high incidence of HIV. Information on the demographics and outcome is necessary for the control of the disease. The demographic characteristics and the treatment outcome of PTB have not been reported in Abubakar Tafawa Balewa Teaching Hospital (ATBUTH) Bauchi. Therefore, this study was aimed to describe the sociodemographic characteristics and determine the treatment outcome of the patients attending the Directly Observed Treatment Short course (DOTS) clinic at the institution. Demographic and outcome variables were extracted from the medical records and patient treatment by using a standard structured questionnaire and the results were express in percentages and frequencies. $A$ total of two hundred and fifty nine (259) PTB patients records were extracted and entered into the study data base. Their Gender distribution was $146(56 \%)$ males and $113(44 \%)$ females age range of $15-70$ years. Majority of the patient were civil servants with some level of education and earned less than thirty thousand $(\$ 30,000)$ Naira, approximately sixty five dollars (\$65) monthly. Most of them lived less than 5 Kilometres from the clinic. Eighty percent $(80 \%)$ of patients were successfully treated while in $20 \%$ were not successfully treated. This study showed that pulmonary tuberculosis affects mostly the most productive age group of the population with some level of education and low income. The success rate of treatment falls short of the recommended success rate suggested by WHO. There is need for further studies to identify the factors responsible for failure to achieve the WHO recommendation as well as factors responsible for unsuccessful treatment.
\end{abstract}

Keywords: Treatment outcome, Pulmonary tuberculosis, Northeastern Nigeria

\section{INTRODUCTION}

Tuberculosis (TB) continues to constitute a major public health problem in both developing countries and developed nations. It is one of the leading causes of deaths worldwide accounting for $2.5 \%$ of the global burden of disease and $25 \%$ of all avoidable deaths in developing countries (Woldeyohannes et al., 2011). Consequential effect of TB burden is concentrated in Asia and sub-Saharan Africa (which make up $58 \%$ and $28 \%$ of all cases respectively (World Health Organization.
Global tuberculosis report, 2015). According to WHO report (2012) a sat 2012, Nigeria accounted for approximately 162,471 new TB cases in Africa which ranked her $6^{\text {th }}$ in Africa (World Health Organization, 2012).

Tuberculosis is almost always curable if patients with drug susceptible organisms are given sufficient uninterrupted therapy. If untreated, $50 \%-80 \%$ of patients with smear positive TB die and in a poorly implemented 
026 J. Med. Med. Sci.

TB programme, as many as $30 \%$ of patients with smear positive TB die (Mugusi et al., 2009). Effective TB treatment has been shown to have a significant effect on the control of the disease, and completion of treatment of active cases has been found to be the most important priority of TB controls programs (Belay et al., 2016). The World Health Organization (WHO) TB control initiative of directly observed treatment short course (DOTS) strategy has effectively control TB pandemic based on report of documented studies (World Health Organization, 1994). Despite, the success recorded with the control strategy, difficulty is still being encountered in some African as the TB incidence continued to increase. Reasons for this scenario have been attributed to some many factors (Grange and Festenstein, 1993), (Hernández et al., 2010).

Treatment outcomes are classified as successful (cure/completed) or unsuccessful (lost to followup/failure/death) (World Health Organization, 1994). Successful treatment of TB involves taking anti tuberculosis drugs for at least six months. Poor adherences to treatment means patient remain infectious for longer time, are more likely to relapse or succumb to tuberculosis and could result in treatment failure as well as foster emergence of drug resistant tuberculosis (Erhabor et al., 2000).

Lost to follow-up is one of the major human dimensions that hinder tuberculosis control. It allows the infected individual to spread the disease to the community thereby giving the organism the opportunity to strive. For new smear-positive pulmonary TB patients, the $\mathrm{WHO}$ set targets are $85 \%$ cure rate, $5 \%$ treatment completed, $1-2 \%$ treatment failure, $2-3 \%$ deaths, $5 \%$ lost to follow-up, and 5\% transfer out (World Health Organization, 1996)

Several studies have reported varied overall treatment default and unsuccessful outcome, in Brazil, overall treatment default ratio of $20.9 \%$ and the unsuccessful outcome rate of $24.1 \%$. (Belo et al., 2011), in South Ethiopia, overall defaulting treatment rate of $11.4 \%$ (Tessema et al., 2009), in Northern Ethiopia unsuccessful treatment outcome, of $18.3 \%$ which accounted for $10.1 \%$ mortality and treatment failure of $0.2 \% y$ (Biru and Lindtjørn 2007). In Nigeria, TB treatment success rate increased from $79 \%$ in 2002 to $85 \%$ in 2003 , however, the default rate remained as high as $11 \%$ and death rate of $6.7 \%$ (Global Tuberculosis Programme, 2005). Studies from North-central and Southwestern region of Nigeria showed $44.2 \%$ and $27 \%$ default rate respectively (Salami and Oluboyo, 2003), (Erhabor et al., 2003).

The study site is one of the major referral centres for TB DOTS programmes, therefore, the retrospective tends to evaluate the TB DOTS treatment success rate in the northeastern Nigeria, and compared with the rate reported within and outside Nigeria. The retrospective study extracted the demographic variables of PTB patient on DOTS attending ATBUTH, Bauchi, and analyzed the success rate.

\section{METHODOLOGY}

\section{Study design}

The retrospective study was conducted on TB patients attending Directly Observed Treatment Short Course (DOTS) clinic of the Abubakar Tafawa Balewa University Teaching Hospital between July 2013 to July 2015.

The hospital is a 750- bed tertiary health care facility that provides specialist services and served as a major referral centre in Northeast region of Nigeria and other neighboring states. The TB DOTs Clinic is supported by the National Tuberculosis and Leprosy Control Programme (NTLCP) Bauchi State Coordinating unit. Treatment Procedures, Laboratory Diagnosis and the Drug Regimens are provided according to the national Policy on TB and Leprosy Progrmme (Federal Ministry of Health, Nigeria, 2008).

\section{Definitions}

According to WHO (The Stop TB Strategy, 2006), treatment outcomes are categorized into successful outcome, if TB patients were cured (negative smear microscopy at the end of treatment and on at least one previous follow-up test) or completed treatment with resolution of symptoms; and unsuccessful outcome if the treatment resulted in failure (remaining smear-positive after 5 months of treatment), defaulted (patients who interrupted their treatment for two consecutive months or more after registration), or died.

\section{Data collection}

Data were extracted from the medical records and patient treatment cards by using a standard structured questionnaire. Information retrieved from the records includes socio-demographic profile of the patients, date of TB diagnosis and treatment outcome and the end of 6 month treatment those there were transferred out were excluded from the study because the treatment outcome is not known. In addition to standard outcome definitions, we classified the final treatment outcome as, successful (cured or treatment completed) or unsuccessful (death, loss to follow-up, or failure). The administration of the questionnaires was done by the TB DOTs health officers who were certified by the investigator. 
Table 1. Socio-demographic Characteristics of tuberculosis patients on DOTS $(n=159)$

\begin{tabular}{|c|c|c|}
\hline \multicolumn{2}{|l|}{ Variables } & \multirow{2}{*}{$\begin{array}{c}\text { Number (\%) } \\
50(19)\end{array}$} \\
\hline Age (Years) & $15-24$ & \\
\hline & $25-34$ & 69(27) \\
\hline & $35-44$ & $62(24)$ \\
\hline & $45-54$ & $41(16)$ \\
\hline & $55-64$ & $19(8)$ \\
\hline & $>64$ & $18(7)$ \\
\hline \multirow[t]{2}{*}{ Gender } & Male & $146(56)$ \\
\hline & Female & $113(44)$ \\
\hline \multirow{4}{*}{ Marital Status } & Single & $93(35.9)$ \\
\hline & Married & $158(61.0)$ \\
\hline & Divorced & $5(1.9)$ \\
\hline & Widowed & $3(1.2)$ \\
\hline \multirow[t]{4}{*}{ Education Level } & Non-Formal & $6(2)$ \\
\hline & Primary & $44(17)$ \\
\hline & Secondary & $92(36)$ \\
\hline & Tertiary & $117(45)$ \\
\hline \multirow[t]{6}{*}{ Occupation } & Farming & $11(4)$ \\
\hline & Civil Servant & $94(36)$ \\
\hline & Housewife & $62(24)$ \\
\hline & Trader & $9(4)$ \\
\hline & Student & $59(23)$ \\
\hline & Business & $24(9)$ \\
\hline \multirow[t]{4}{*}{ Estimated Monthly Income (Naira) } & $<30,000$ & $196(76)$ \\
\hline & $30-50,000$ & $54(21)$ \\
\hline & $50,000-100,000$ & $6(2)$ \\
\hline & $>100,000$ & $3(1)$ \\
\hline \multirow[t]{4}{*}{ Distance from the DOT clinic $(\mathrm{Km})$} & $<1$ & $40(15)$ \\
\hline & $1-4$ & $178(69)$ \\
\hline & $5-9$ & $13(5)$ \\
\hline & $>10$ & $28(11)$ \\
\hline
\end{tabular}

\section{Data analysis}

Socio-demographic variables and treatment outcome data were entered into the study database, and analyzed using SPSS version 17.0, the values expressed in frequencies and percentages.

\section{Ethical consideration}

The study protocol was approved by the Research and Ethics Committee of the ATBUTH Bauchi. In order to protect the confidentiality of the information, names and hospital numbers of the patients were not included in data extraction questionnaire.

\section{RESULTS}

Data of two hundred and fifty nine (259) TB patients on DOTS were extracted and analyzed. The sociodemographic variables of the patient as presented on table 1, Gender distribution, $146(56 \%)$ were males and $113(44 \%)$ females giving M; F ratio of and aged range of 15-70 years while. Majority of the patients were within the age group of $25-34$ years. Only $7 \%$ of the patients were above the age of 64 years. Marital status showed that Sixty one percent were married. On educational background, $90 \%$ had one form of educational knowledge, but (45\%) had tertiary education. Occupations, showed that majority of the patients were civil servants, $(36 \%)$, housewives $(24 \%)$ or students 
028 J. Med. Med. Sci.

Table 2. Treatment Outcomes of tuberculosis patients: $(n=259)$

\begin{tabular}{lc}
\hline Treatment outcome & Number (\%) \\
\hline Successful & $208(80)$ \\
Unsuccessful & $51(20)$ \\
Total & $259(100 \%)$ \\
\hline
\end{tabular}

Table3. Reasons for unsuccessful Treatment outcome in tuberculosis patients: $\mathrm{n}=51$

\begin{tabular}{lc}
\hline Reason & Number (\%) \\
\hline Lost to Follow-up & $41(80)$ \\
Treatment failure & $2(4)$ \\
Died & $8(16)$ \\
Total & $51(100 \%)$ \\
\hline
\end{tabular}

(23\%). The income of the patient showed $76 \%$ ) earned less than thirty thousand ( $\$ 30,000$ ) Naira approximately sixty five dollars $(\$ 65)$ as estimated monthly income with only9 (3\%) of them earning $\$ 50,000$ or more per month. Considering the distance of the TB DOTS centre to the patients sampled, Majority of the patients 178(69\%) lived less than $5 \mathrm{Km}$ from the clinic. Only $11 \%$ live at a distance of more than 10 Kilometers.

Based on the WHO success treatment definition (table2), 80 (80\%) of patients were successfully treated while in $20 \%$ showed unsuccessful treatment outcome. Of the 259 patients, 51(16.6\%) had unsuccessful treatment outcome, $41(80 \%)$ were lost to follow up, $2(4 \%)$ treatment failure and $4(16 \%)$ died. (table3)

\section{DISCUSSION}

This study showed that pulmonary tuberculosis affects mostly the most productive age group of the population unlike in developed countries where TB affects mostly the elderly (P D O Devies, 1999) which is similar with other the findings of other studies (Jibrin et al., 2013), (Erhabor et al., 2003), (Kochi 1999). These are active, skillful, experience and mobile individual that drive the economy of the developing nation (Armstrong 1995). Therefore the economic development of the community would be affected and the spread of the infection into the population would be accelerated. The result also indicated that males are affected more than female and as males are mostly the income earners in this community, this further affects the family income. This leads to a vicious cycle as the disease affects mostly those with poor living condition and low socioeconomic status as supported by the findings of (Fatiregun et al., 2009) and (Salami and Oluboyo, 2003) from southwestern and North-central part of Nigeria respectively. This stresses the urgent need for the control and treatment of Tuberculosis to break this circle. Majority of the patients were married. The practice of polygamy in this community is very common and people leave in overcrowded setting with large number of children and the elderly who are vulnerable to infection by Tuberculosis. The implication is that once a member of the family is infected, the chance of spreading the disease to other members of the family is high (Belo et al., 2011).

Majority of the patients had some level of education with many of them attaining a tertiary education. The proportion of this educated group is higher than reported from Ibadan, Nigeria ${ }^{26}$

The likely biased as most of the patients are civil servants who were registered with national health insurance scheme, which makes it more convenient to seek for medical care in this centre. Despite the fact that majority of the patients have some level of education and are civil servants, the monthly income of most of them is less than 30,000 Naira. This further showed that low income is a major risk factor in the development of pulmonary Tuberculosis in our community which is consistent with reports from Ibadan (Akinola et al., 2004) and Ife (Erhabor et al., 2003).

Most of the patients in our study lived less than $5 \mathrm{Km}$ from the clinic thus making it easier for them collect their drugs without much cost on transportation and time spending. This will have positive effect on the compliance and reduce the chances of lost to follow-up. A similar finding was documented by (Jibrin et al., 2013). In some 
studies, the patients have to travel a distance of more than $7 \mathrm{Km}$ to the treatment centre and that implicate poor treatment outcome (Lisha et al., 2012), (Lake et al., 2011), (Babatunde et al., 2012).

The success rate of treatment in this study falls short of the recommended minimum $80 \%$ success suggested by the World Health Organization (WHO) (Global Tuberculosis Programme, 2005). There is need for further studies to identify the factors responsible for failure to achieve the WHO recommendation. The rate of unsuccessful treatment in our study is higher than what was reported from Hong Kong (Morsy et al., 2003), however, it is lower than what was reported from Shagamu, Southwestern Nigeria (Chan Yeung et al., 2003)

The treatment failure rate was lower than the rate found in tertiary hospital settings in southwestern Nigeria (Daniel et al., 2006), (Amoran 2011). However it is higher than the findings in a study conducted in Southeastern Nigeria (Isaac et al., 2014). Several reasons for the unsuccessful treatment were provided by some studies which include, previous exposure to anti TB treatment, poor knowledge of the duration treatment, unfriendly attitude of health care workers towards the patients, nonadherence to the drug regimen, drug resistance, mal absorption of drugs, laboratory error and not having received family support (Ibrahim et al., 2015), (Jha et al., 2010), (Gupta et al., 2011), (Fatiregun et al., 2009), (CDC. Treatment of Tuberculosis, American Thoracic Society 2003), (Maria et al., 2007). Since the study was a prospective review of records of the patients, it was not possible to evaluate the factors responsible for unsuccessful treatment. Therefore further prospective studies on factors associated with unsuccessful treatment in our environment are needed.

\section{CONCLUSION}

This study showed that pulmonary tuberculosis affects mostly the most productive age group of the population with some level of education and low income. The success rate of treatment falls short of the recommended minimum $80 \%$ success suggested by the World Health Organization and the treatment failure rate if is great concern. There is need for further studies to identify the factors responsible for failure to achieve the WHO recommendation as well as factors responsible for unsuccessful treatment.

\section{REFERENCES}

Akinola AF, Abinbola SO, Afolabi EB (2004). Treatment Outcome among Tuberculosis Patient at Treatment Centre in Ibadan, Nigeria. Annals of African Medicine: Vol 8, no. 2:100-104
Amoran OE (2011). Determinants of treatment failure among tuberculosis patients on directly observed therapy in rural primary health care centres in Ogun State, Nigeria Prim. Health Care, 1 p. 104

Armstrong J (1995). Uganda's AIDS Crisis: Its Implications for development. World Bank Discussion Paper: 39, 47, 54.

Babatunde OA, Elegbede OE, Ayodele LM, Ojo OJ, Ibironbge DO (2012). Two year trend analysis of default rate in tuberculosis patients in federal medical centre, Ido-Ekiti State, Nigeria. Journal of Asian Scientific Res.; 2(12):798-806.

Belay MB, Abrha YH, Fisseha SB (2016). Treatment outcome of Tuberculosis and associated factors in an Ethiopian University Hospital: Advances in Public Health.; 2016:1 [Pubmed] | [DOI]

Belo MT, Luiz RR, Teixeira EG, Hanson C, Trajman A (2011). Tuberculosis treatment outcomes and socio-economic status: a prospective study in Duque de Caxias, Brazil, Int J Tuberc Lung Dis., 15(7) 978-81

Biru E, Lindtjørn B (2007). Determinants of Treatment Adherence among Smear-Positive Pulmonary Tuberculosis Patients in Southern Ethiopia. PLoS Medicine.; 4(2): 0001-0008. PubMed | Google Scholar

CDC. Treatment of Tuberculosis, American Thoracic Society: CDC, and Infectious disease Society of America. MMWR. 2003 June 20; 52(11). PubMed | Google Scholar

Chan Yeung M, Noertjojo K, Leung CC, Chan SL, Tam CM (2003). Prevalence and predictors of default from Tuberculosis Treatment in Hong Kong. Hong Kong Medical J;9:63-68

Daniel OJ, Oladapo OT, Alausa OK (2006). Default from Tuberculosis Treatment in Shagamu, Nigeria; Nigerian J. Med., Vol. 15 no. 1:

Erhabor GE, Adebayo RA, Omodara JA, Famurewa OC (2003). Ten year review of patterns of presentation and outcome of pulmonary tuberculosis in OAUTHC, lle-Ife, Nigeria. J Health Sci;3:34-9

Erhabor GE, Adebayo RA, Omodara JA, Famurewa OC (2003). Ten year review of pattern of presentation and outcome of pulmonary Tuberculosis in OAUTH Ile Ife. Nigerian J Health Sci;3:34-9

Erhabor GE, Aghanwa HS, Yusuph M, Adebayo RA, Arogundade FA, Omidiora $A$ (2000). Factors influencing compliance in patients with tuberculosis on directly observed therapy at Ile-Ife, Nigeria, East Afr Med J., 77(5) 235-9.

Fatiregun AA, Ojo AS, Bamgboye AE (2009). "Treatment Outcomes among Pulmonary Tuberculosis Patients at Treatment Centers in Ibadan, Nigeria." Annals of African Medicine 8 (2): 100-4.

Fatiregun AK, Ojo AS, Bamgboye AE (2009). Treatment outcomes among pulmonary tuberculosis patients at treatment centres in Ibadan, Nigeria. Annals of African Medicine; 8 (2): 100-104

Federal Ministry of Health, Nigeria (2008). "National TB and Leprosy Control Programme" Annual Report,http://ntblc.org/report/annual

Global Tuberculosis Programme. Global Tuberculosis Control: Surveillance, Planning, and financing. WHO report 2005 (rep no WHO/HTM/TB/2005.349). Geneva: World Health Organization; 2005. P.108-11

Grange MJ, Festenstein F (1993). The human dimension of tuberculosis control. Tuber. Lung Dis., 74: 219-222

Gupta S, Behera D (2011). "Reasons for Interruption of anti-Tubercular Treatment as Reported by Patients with Tuberculosis Admitted in a Tertiary Care Institute." Indian J. Tuberc. 58 (1): 11-7.

Hernández R, Pacheco, Ferro BE (2010). Clinical, epidemiological and microbiological characteristics of a cohort of pulmonary tuberculosis patients in Cali, Colombia, Biomedica, 30(4) 482-91.

Ibrahim LM, Hadejia IS, Nguku P, Lakda GM, Ogiri S, Patrobas P (2015). Factors Associated with Outcomes of Treatment among Pulmonary Tuberculosis Patients in Plateau State, Nigeria, 2011; J. US-China Medical Sci. 12 172-179 doi: 10.17265/15486648/2015.04.005:

Isaac A, Daniel C, Oshi S, Oshi N, Kingsley NU (2014). Profile and determinants of treatment failure among smear-positive pulmonary tuberculosis patients in Ebonyi, Southeastern Nigeria; International J. Mycobacteriology Vol. 3, Issue 2, June, Pages 127-131

Jha UM, Satyanarayana S, Dewan PK, Chadha S, Wares F, Sahu S, 
030 J. Med. Med. Sci.

Gupta D, Chauhan LS (2010). "Risk Factors for Treatment Default among re-Treatment Tuberculosis Patients in India, 2006." PLoS ONE 5 (1): e8873.

Jibrin YB, Ali AB, Saad ST, Kolo PM (2013). Prevalence of treatment Failure among Tuberculosis Patients in Federal Medical Centre Gombe, Northeast Nigeria: ISRN Infectious Disease Vol.2013 Article $461704 \mathrm{http}: / / \mathrm{dx}$.doi.org/10.5402/2013/461704

Kochi A (1999). A global Tuberculosis situation and the new control strategy of the world health Organization. Tubercule;72:1-6

Lake IR, Jones NR, Bradshaw L, Abubakar I (2011). Effects of distance to treatment centre and case load upon tuberculosis treatment completion. Eur Respir J.; 38(5):1223-5. DOI: 10.1183/09031936.00036211

Lisha PV, James PT, Ravindran C (2012). Morbidity and mortality at five years after initiating category 1 treatment among patients with new sputum smear positive pulmonary tuberculosis. Indian J. Tuberc.; 59(2):83-91.

Maria F, Ricardo X, Wayner S, Andrea D, Odimariles S (2007). Factors associated with treatment failure, dropout, and death in a cohort of tuberculosis patients in Recife. Pernambuco State, Brazil Cad SaudePublica. July; 23 (7). PubMed | Google Scholar

Morsy AM, Zaher HH, Hassan MH, Shouman A (2003). Predictors of treatment failure among tuberculosis patients under DOTS strategy in Egypt East. Mediterr. Health J., 9 pp. 689-701

Mugusi FM, Mehta S, Villamor E (2009). Factors associated with mortality in HIV-infected and uninfected patients with pulmonary tuberculosis. BMC Public Health.;9:409-16.10.1186/1471-2458-9409 [CrossRef], [PubMed], [Web of Science $\AA$ ]

P D O Devies (1999). The effect of Poverty and ageing on the increase in Tuberculosis" Monaldi Achieves of chest Disease, Vol 54.No 2 pp. 168-171.
Salami AK, Oluboyo PO (2003). Management outcome of pulmonary Tuberculosis: a 9 review of llorin. West Afr J Med; 22:114-9

Salami AK, Oluboyo PO (2003). Management outcome of Pulmonary Tuberculosis: A nine Year Review in Ilorin. West African Journal of Med. Vol. 22, no 2, pp. 114-19.

Tessema B, Muche A, Bekele A, Reissig D, Emmrich F, Sack U (2009). Treatment outcome of tuberculosis patients at Gondar University Teaching Hospital, Northwest Ethiopia: a five - year retrospective study. BMC Public Health.; 9(371). PubMed | Google Scholar

The Stop TB Strategy: building on and enhancing DOTS to meet the TB related Millennium Development Goals. Geneva, World Health Organization, 2006 (WHO/HTM/STB/2006.37)

Woldeyohannes D, Kebede N, Erku W, Tadesse Z (2011). Ten years' experience of directly observed treatment short-couse (dots) therapy for tuberculosis in Addis Ababa, Ethiopia, Ethiop Med J., 49(3) (221-9.

World Health Organization (1994). Framework for Effective Tuberculosis Control. WHO/TB/94.179. Geneva

World Health Organization (1996). Managing tuberculosis at the RHU level: Quarterly reporting on treatment result, TB Control Service, Department of Health

World Health Organization (2012). Global Tuberculosis Report; Geneva: 1-3,36-49,74-76

World Health Organization. Global tuberculosis report (2015). Geneva: WHO. 